\title{
PERFIL NUTRICIONAL DA DIETA DOS PRÉ-ESCOLARES DO MUNICÍPIO DE NHAMUNDÁ-AM., BRASIL
}

\section{Lúcia K. O. YUYAMA*; Jaime P. L. AGUIAR*; Sonja H. Madeira MACEDO*; Lina YONEKURA*; Dionísia NAGAHAMA*; Fernando Hélio ALENCAR*}

RESUMO - Determinou-se os constituintes nutricionais das dietas dos pré-escolares do Município de Nhamundá-AM, seguido da adequação dos mesmos. Utilizou-se a técnica de amostragem da porção em duplicata, que consistiu em coletar todos os alimentos e bebidas consumidos durante um dia para a avaliação dietética. Os resultados mostraram uma baixa adequação calórica, além das deficiências para os elementos minerais ferro, cálcio e zinco.

Palavras-chave: nutrição, adequação nutricional.

Nutritional Profile of the Pre-School Children Diet from Nhamundá-Amazonas, Brazil.

ABSTRACT - It was determined the nutritional constituents of the pre-school children diets from Nhamundá - AM, followed by the nutrient adequacy ratio. For sampling, the duplicate portion technique was used, which consisted of collecting all the foods and beverages consumed during 1 day. The results shown inadequate caloric contents, besides presenting deficiency of iron, calcium and zinc.

Key-words: nutrition, adequacy nutritional.

A desnutrição é uma realidade que ocorre há anos na Região Amazônica (Hartman \& João,1978, Giugliano et al., 1984, INAN, 1990), e está diretamente associada às condições sócio-econômicas, higiênico-sanitárias e cultural da população. Alguns estudos realizados em pré-escolares da região mostram que as deficiências nutricionais incluem desnutrição crônica, deficiência energética e de vitaminas como niacina, vitamina $\mathrm{A}$, e anemias associadas a parasitoses intestinais (Marinho et al., 1992). Entretanto, o perfil alimentar de pré-escolares na área rural do Estado do Amazonas ainda é pouco conhecido.

Considerando a escassez de informações quanto ao perfil alimentar em pré-escolares da Amazônia, em especial da área rural do Estado do

Amazonas, e a relevância destas informações para o processo de prevenção e/ou intervenção nutricional, determinou-se os constituintes nutricionais da dieta de pré-escolares do Município de Nhamundá-AM, assim como a adequação dos mesmos.

O estudo foi realizado em novembro de 1997 utilizando-se uma sub-amostra de 44 dietas de 182 préescolares do Município de Nhamundá, $\mathrm{AM}$, situado à margem direita do rio Nhamundá, afluente do rio Amazonas$\mathrm{AM}$, onde coletou-se a porção da dieta em duplicata de um dia, procedendose posteriormente a análise química de seus constituintes. Considerando que nas áreas Ribeirinhas não há variação em relação aos alimentos freqüentemente

* Laboratório de Nutrição e Físico-Química de Alimentos-CPCS - Instituto Nacional de Pesquisas da Amazônia/INPA. Alameda Cosme Ferreira, 1756, Aleixo, Manaus/AM. CEP: 69083-000. 
consumidos, de acordo com a nossa constatação "in loco", e também, por questão ética, pois muitas vezes as crianças são penalizadas por não terem o que consumir, optou-se pela coleta de um dia, que ao nosso ver é representativa.

A análise quimica das dietas seguiu as normas da AOAC (1995). Quanto ao teor de fibra alimentar solúvel, insolúvel e total, seguiu-se o método enzímico-gravimétrico de ASP et al (1983), e para os elementos minerais macro $(\mathrm{Ca}, \mathrm{Na}, \mathrm{K}, \mathrm{Mg})$ e micro (Fe, $\mathrm{Zn}, \mathrm{Cu}, \mathrm{Mn}$ ), utilizando o método espectrofotométrico de absorção atômica (AAS), após digestão por via úmida $\left(\mathrm{HNO}_{3} / \mathrm{H}_{2} \mathrm{O}_{2}\right)$. Como material de referência utilizou-se o material certificado Peach Leaves (NISTSRM 1547). Para o cálculo de adequação nutricional seguiu-se as recomendações da National Research Council-RDA (NAS/
NRC1989) para pré-escolares na faixa etária de 4 a 6 anos.

De acordo com os resultados obtidos verificou-se que os alimentos mais freqüentemente consumidos foram: farinha de mandioca, pão, arroz e peixe (Fig. 1), esta frequência alimentar é condizente com os resultados encontrados por Yuyama et al. (1997). A quantidade de fibra insolúvel encontrada na dieta analisada foi baixa $(6,3 \mathrm{~g} / \mathrm{dia})$ e o teor de fibra solúvel não foi detectado (Tab. 1). Tal fato pode ser, provavelmente, reflexo do baixo consumo de alimentos ricos em fibra como por exemplo frutas e verduras, demonstrado no inquérito alimentar (Fig. 1). Estes resultados refletem a forte influência do fator cultural arraigado na população amazônida em não consumir verduras conforme já mencionado em trabalhos anteriores

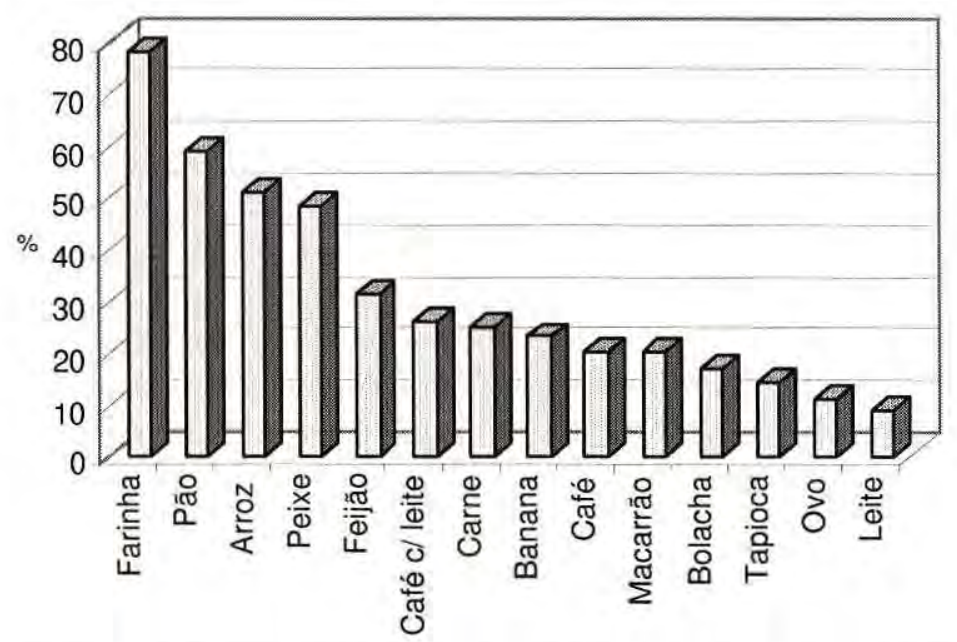

Figura 1. Frequência de consumo de alimentos na dieta de pré-escolares do Município de Nhamundá, Am. 
Tabela 1. Composição centesimal e energia da dieta de pré-escolares do Município de Nhamundá, Am.

\begin{tabular}{lccccccc}
\hline Umidade & $\begin{array}{c}\text { Nifext } \\
(\mathrm{g})\end{array}$ & $\begin{array}{c}\text { Proteina } \\
(\mathrm{g})\end{array}$ & $\begin{array}{c}\text { Lipídio } \\
(\mathrm{g})\end{array}$ & $\begin{array}{c}\text { Cinza } \\
(\mathrm{g})\end{array}$ & $\begin{array}{c}\text { Fibra } \\
\text { insolúvel } \\
(\mathrm{g})\end{array}$ & $\begin{array}{c}\text { Fibra } \\
\text { solúvel } \\
(\mathrm{g})\end{array}$ & $\begin{array}{c}\text { Calorias } \\
(\mathrm{Cal})\end{array}$ \\
\hline 64,30 & 26,13 & 5,15 & 2,04 & 1,09 & 1,29 & 0 & 143,48 \\
\hline
\end{tabular}

(Giugliano et al., 1978).

A adequação protéica foi superior a $100 \%$, e o valor energético muito baixo, $38,9 \%$. Entretanto, o consumo inadequado de calorias possivelmente provoca o desvio metabólico da proteína, fazendo com que supra as necessidades energéticas, prejudicando, desta maneira, a sua função principal ou seja a plástica. Os resultados se assemelham aos encontrados por Yuyama et al. (1997). Isto demonstra que o problema nutricional dos préescolares da área rural do Estado do Amazonas não é protéico e sim calórico, provavelmente, pelo hábito tradicional referente ao consumo de peixes, dependendo dos fatores sazonais e do local estudado. Tal constatação necessita de ações estratégicas imediatas no que se refere a oferta calórica, objetivando-se evitar a ocorrência de desnutrição energético-protéica. A adequação do consumo de $\mathrm{Cu}$ e $\mathrm{Na}$ apresentou-se superior a $100 \%$. Os demais elementos minerais apresentaram adequação inferiores a $70 \%$, sendo $\mathrm{Ca}$ e $\mathrm{Zn}$ os elementos com menor porcentagem de adequação (Tab. 2).

Conclui-se que a dieta dos préescolares do Município de NhamundáAM apresentou baixo consumo de frutas e verduras, déficit energético, e,

Tabela 2. Consumo médio e porcentagem de adequação de proteina, calorias e minerais da dieta dos pré-escolares do Município de Nhamundá, Am.

\begin{tabular}{|c|c|c|c|}
\hline Nutrientes & Consumo médio & $\begin{array}{c}\text { RDA }(1989)^{*} \\
4-6 \text { anos }\end{array}$ & $\%$ de adequação \\
\hline Proteína $(\mathrm{g})$ & 25,16 & 24 & 104,8 \\
\hline Calorias (Cal) & 403,37 & 1800 & 22,4 \\
\hline $\mathrm{Na}(\mathrm{mg})$ & 1376,5 & 300 & 458,8 \\
\hline $\mathrm{K}(\mathrm{mg})$ & 634,23 & 1400 & 45,3 \\
\hline $\mathrm{Ca}(\mathrm{mg})$ & 177,51 & 800 & 22,2 \\
\hline $\mathrm{Mg}(\mathrm{mg})$ & 78,24 & 120 & 65,2 \\
\hline $\mathrm{Cu}(\mathrm{mg})$ & 3,84 & $1-1,5$ & $384,0-256,0$ \\
\hline $\mathrm{Fe}(\mathrm{mg})$ & 4,13 & 10 & 41,3 \\
\hline $\mathrm{Mn}$ (mg) & 1,05 & $1,55-2,0$ & $69,8-52,3$ \\
\hline $\mathrm{Zn}(\mathrm{mg})$ & 2,88 & 10 & 28,8 \\
\hline
\end{tabular}


aparentemente adequação em proteina, necessitando-se da comprovação biológica quanto à sua utilização. Com relação aos elementos minerais, sódio e cobre foram os elementos com maior porcentagem de adequação, entretanto o cálcio apresentou adequação baixíssima, seguido do zinco. Vale ressaltar que a baixa adequação dos elementos minerais é preocupante, por se tratar de nutrientes importantes no crescimento e desenvolvimento do grupo estudado.

\section{AGRADECIMENTOS}

À FINEP pelo suporte financeiro, $\mathrm{CNPq}$, INPA e Laboratório de Solos da CCCA, pelo apoio.

\section{Bibliografia citada}

Asp, N.G.; Johansson, C.G.; Hallmer, H.; Siljestrom, M. 1983. Rapid enzymatic assay of insoluble and soluble dietary fiber. J. Agric. Food. Chem., Washington, 31: 476-482,

AOAC. 1995. Association Of Official Analytical Chemists/ Official methods of analyses. 16 ed. Arlington. $1141 \mathrm{p}$.

Giugliano, R.; Shrimpton, R.; Marinho, H.A.; Giugliano, L. G. 1984. Estudos nutricionais das populações rurais da Amazônia. II. Rio Negro, Acta Amazonica, 14(3-4): 427-449.

Giugliano, R.; Shrimpton, R.; Arkcoll, D.B..;
Giugliano, L. G.; Petrere Jr., M. 1978. Diagnóstico da realidade alimentar e nutricional do Estado do Amazonas. Acta Amazonica, 8(2): Suplem., 54p.

Hartman, A.F.; João, W.S.J. 1978. Desnutrição protéico-calórica na região Centroamazônica: relatório preliminar da prevalência e fatores demográficos. J.Ped., 45( 5): 323-332,

INAN. 1990. Instituto Nacional de Alimentação e Nutrição Pesquisa Nacional sobre Saúde e Nutrição. Perfil de crescimento da população brasileira de 0-25 anos. Brasília/DF, $59 \mathrm{p}$.

Marinho, H.A.; Kazapi, I.M.; Fernandes, M. H.A.; Guedes, M.R . 1992. Avaliação do estado nutricional de pré-escolares de classe sócio-econômica média e baixa da cidade de Manaus: Estudo comparativo. Acta Amazonica, 22(3): 363-368.

NAS/NRC. 1989. National Academy Of Science/National Research Council. Recommended Dietary Allowances. 10 ed. Washington, $284 \mathrm{p}$.

Yuyama, L.K.O.; Aguiar, J.P.L.; Alencar, F.H.; Macedo, S.H.M.; Fávaro, D.L.T. 1997. Avaliação nutricional da dieta de préescolares do municipio de Barcelos, AM. In: Congresso Brasileiro de Pediatria, 30 , Rio de Janeiro. Anais do XXX Congresso Brasileiro de Pediatria: Arquivos Brasileiros de Pediatria, 4 (supl.1): 145. 